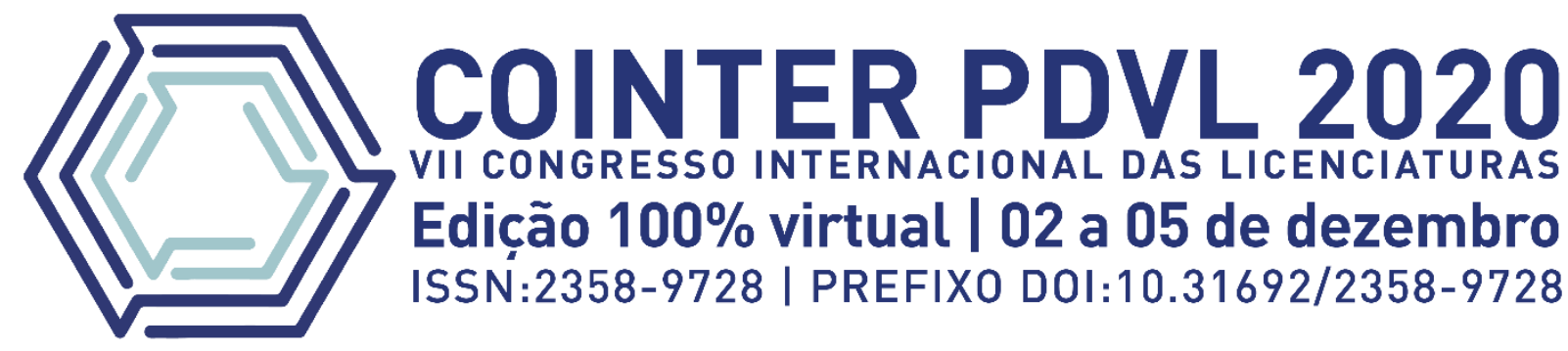

\title{
A AÇÃO PEDAGÓGICA DO PROFESSOR FRENTE A ABORDAGEM BILINGUE: UMA EXPERIÊNCIA FORMATIVA EM LIBRAS
}

\section{LA ACCIÓN PEDAGÓGICA DEL MAESTRO FRENTE AL ENFOQUE BILINGÜE: UNA EXPERIENCIA FORMATIVA EN LIBRAS}

\section{THE TEACHER'S PEDAGOGICAL ACTION IN FRONT OF THE BILINGUAL APPROACH: A FORMATIVE EXPERIENCE IN LIBRAS}

\author{
Apresentação: Comunicação Oral \\ Jaqueline Costa da Silva Lima ${ }^{1}$; José Roniero Diodato ${ }^{2}$; Lúcio Costa de Andrade ${ }^{3}$ Layse da Costa Santos ${ }^{4}$; \\ Ayrton Matheus da Silva Nascimento ${ }^{5}$
}

DOI: https://doi.org/10.31692/2358-9728.VIICOINTERPDVL.0295

\begin{abstract}
RESUMO
Este artigo traz uma reflexão sobre a importância da ação do professor frente a abordagem bilíngue enquanto uma experiência formativa em Libras (Língua Brasileira de Sinais) e seus impactos no desenvolvimento escolar do sujeito surdo. A pesquisa é de caráter bibliográfico, no qual utilizamos a análise documental de autores que discutem sobre o tema dentre eles destacam-se Fernandes e Reis (2019), Perlin (2010), Quadros (2011) e das bases legislativas que direcionam e asseguram a educação inclusiva no Brasil. É possível compreender que pelo fato de vivermos em uma sociedade com uma língua majoritária oral auditiva, cabe aos que vivem nela adequarem-se linguisticamente. E, neste caso os surdos que usam uma língua visual-espacial, a Libras, considerados uma minoria linguística, ou seja, usam uma língua inferior. Nesse viés, é relevante abordar discussões acerca dos aspectos sobre a formação continuada dos professores em Libras, visto que cada vez mais alunos surdos estão ingressando em escolas de ensino regular e uma abordagem bilíngue seria o primeiro passo para que o desenvolvimento do aluno surdo ocorresse de forma satisfatória, uma vez que é necessário também que o professor tenha conhecimento acerca das metodologias de ensino inclusivas alinhadas com a cultura surda fator fundamental para formação dos processos identitários e culturais. Por vez, ficou claro que os profissionais que trabalham com surdos precisam refletir sobre a importância da Libras em processo de ensino e aprendizagem e a partir disso começarem a mudar as metodologias aplicadas em sala de aula e assim contribuir de forma significativa para a alfabetização desses sujeitos numa perspectiva bilíngue. Palavras-Chave: Ação Pedagógica, Abordagem Bilíngue, Libras.
\end{abstract}

\footnotetext{
1 Pedagoga, Graduanda em Letras Libras, pelo Centro Universitário Leonardo Da Vinci/UNIASSELVI, Especialista em Psicopedagogia Clínica pela UNIFACOL e Proficiência em Tradução e Interpretação da Libras pela ALPHA, jaqueline.costal@ufpe.br

${ }^{2}$ Pedagogo, Graduando em Letras Libras, Universidade Federal de Pernambuco/UFPE, roniero.diodato@ufpe.br ${ }^{3}$ Pedagogo, Graduando em Letras Libras, Universidade Federal da Paraíba/UFPB, lucio.costa@ academico.ufpb.br ${ }^{4}$ Licenciada em Letras Libras, UFPE, Graduanda em Letras Português, pela Universidade Estácio de Sá e Especialista em Docência do Ensino Superior, pela Faculdade Joaquim Nabuco, laysecostaa@gmail.com

${ }^{5}$ Mestrando em Educação em Ciências e Matemática - PPGECM, pela Universidade Federal de Pernambuco (UFPE/CAA), Especialista em Ensino de Química e Graduado em Licenciatura em Química pelo Instituto Federal de Pernambuco (IFPE - Campus Vitória), ayrton.nascimento@ufpe.br.
} 


\title{
RESUMEN
}

Este artículo reflexiona sobre la importancia de la acción del docente en relación al abordaje bilingüe como experiencia formativa en Libras (Lengua de Signos Brasileña) y sus impactos en el desarrollo escolar del sujeto sordo. La investigación es de carácter bibliográfico, en la que utilizamos el análisis documental de autores que discuten el tema, entre los que destacan Fernandes y Reis (2019), Perlin (2010), Quadros (2011) y las bases legislativas que orientan y aseguran la educación inclusiva en Brasil. Es posible entender que debido a que vivimos en una sociedad con una lengua auditiva oral mayoritaria, corresponde a quienes viven allí adaptarse lingüísticamente. En este caso, los sordos que utilizan un lenguaje visual-espacial, Libras, son considerados una minoría lingüística, es decir, utilizan un lenguaje inferior. En este sesgo, es relevante abordar discusiones sobre aspectos de la formación continua de docentes en Libras, ya que cada vez son más los estudiantes sordos que ingresan a las escuelas regulares y un enfoque bilingüe sería el primer paso para que ocurra el desarrollo de los estudiantes sordos. satisfactoriamente, ya que también es necesario que el docente tenga conocimientos sobre metodologías de enseñanza inclusivas alineadas con la cultura sorda, factor fundamental para la formación de la identidad y los procesos culturales. Por una vez, quedó claro que los profesionales que trabajan con sordos necesitan reflexionar sobre la importancia de Libras en el proceso de enseñanza y aprendizaje y a partir de ahí empezar a cambiar las metodologías aplicadas en el aula y así contribuir significativamente a la alfabetización de sujetos en una perspectiva bilingüe.

Palabras Clave: Acción Pedagógica, Enfoque Bilingüe, Libras.

\begin{abstract}
This article reflects on the importance of the teacher's action in relation to the bilingual approach as a formative experience in Libras (Brazilian Sign Language) and its impacts on the school development of the deaf individual. The research is of a bibliographic character, in which we use the documentary analysis of authors who discuss the theme, among them stand out Fernandes and Reis (2019), Perlin (2010), Quadros (2011) and the legislative bases that direct and ensure the inclusive education in Brazil. It is possible to understand that because we live in a society with an auditory oral majority language, it is up to those who live there to adapt themselves linguistically. In this case, the deaf who use a visualspatial language, Libras, considered are a linguistic minority, that is, they use an inferior language. In this bias, it is relevant to address discussions about aspects of the continuing education of teachers in Libras, since more and more deaf students are entering regular schools and a bilingual approach would be the first step for the development of deaf students to occur satisfactorily, since it is also necessary for the teacher to have knowledge about inclusive teaching methodologies aligned with deaf culture, a fundamental factor for the formation of identity and cultural processes. For once, it was clear that professionals who work with the deaf need to reflect on the importance of Libras in the teaching and learning process and from that start to change the methodologies applied in the classroom and thus contribute significantly to the literacy of these subjects in a bilingual perspective.
\end{abstract}

Keywords: Pedagogical Action, Bilingual Approach, Libras.

\section{INTRODUÇÃO}

Atualmente vivemos em um mundo altamente globalizado e de constantes mudanças, e na área educacional não ocorre de maneira diferente, pois muitas são as demandas do espaço escolar, e é necessário que os profissionais da área educacional estejam devidamente preparados para atendê-las de forma eficiente.

Por isso, a Lei de Diretrizes e Bases da Educação (LDB 9394/96) que regulamenta o sistema educacional no Brasil, seja ele público ou privado, desde a educação básica até o ensino superior demanda de uma formação continuada dos docentes, associando à importância de ser professor a partir do conceito de formação docente surge como ponto norteador para a busca da 
profissionalização, auxiliando a construção do conhecimento e do discente por meio de aulas dinâmicas (CRUZ E COSTA, 2017).

Nesse cenário, a necessidade de inclusão educacional das pessoas com deficiência ganha força a partir de 2008 quando foi implementada a Política Nacional de Educação Especial na Perspectiva da Educação Inclusiva, na qual visa orientar que todos os alunos da Educação Especial devem frequentar as escolas de ensino regular com direito a um Atendimento Educacional Especializado - AEE em conformidade com uma mudança estrutural e cultural do ambiente escolar, a fim de que as especificidades de cada aluno sejam atendidas (BRASIL, 2008).

Assim, a partir da promulgação da Lei 10.436/2002 que dispõe da Libras (Língua Brasileira de Sinais) como língua natural da comunidade surda brasileira e constitui a educação bilíngue como melhor metodologia de ensino para o aluno surdo, mas contemplando a Língua Portuguesa na modalidade escrita abrem-se novos caminhos no Brasil. Fica claro que, ao se falar de inclusão dos alunos surdos na sala regular não significa que é apenas inseri-los num espaço com o intérprete, pois é necessário compreender sua singularidade linguística e cultural conforme previsto nesta lei.

Por essa razão, o pretendido nesse estudo são algumas reflexões sobre as práticas pedagógicas que dinamizam a ação do professor frente a abordagem bilíngue enquanto uma experiência formativa em Libras. Os sujeitos surdos viveram décadas em busca de uma educação que priorizasse sua língua. Ao realizar uma retrospectiva histórica desse povo, percebe-se o quão grande foram as barreiras encontradas na área da educação como a negação de direitos, assim eram abandonados marginalizados e privados de seus direitos básicos necessários para legitíma-los como cidadãos pertencentes à sociedade.

Além disso, ter esse respaldo legal é muito importante visto que a educação inclusiva é um desafio constante que não permite inércia por parte da equipe escolar. A sala de aula é um ambiente heterogêneo e para que não haja segregação e ocorra um melhor desenvolvimento do discente, independente da sua especificidade, é imprescindível que a formação continuada dos professores ocorra em todas as áreas do conhecimento, bem como em todos os níveis e modalidades de ensino como destaca Fernandes e Reis (2019).

Consequentemente, é necessário pensar na formação continuada dos docentes para a atuação na educação de alunos surdos visando superar as atuais demandas e exigências da prática educacional das escolas, uma vez que a inclusão de discentes com surdez no ensino regular está cada vez mais frequente e tem enfrentado muitas barreiras, das quais é possível destacar comunicação, interação entre os alunos e a falta de capacitação dos docentes para atuar 


\section{A AÇÃO PEDAGÓGICA DO PROFESSOR FRENTE A ABORDAGEM BILINGUE}

com estes alunos como reforçam Feitosa e Silva (2017).

A saber, o pensamento característico de Paulo Freire (2001) afirma que o ser humano é um ser inacabado e a consciência desse inacabamento resulta na ideia de formação permanente. Baseado nesse cenário ressalta-se a importância da formação continuada em Libras para professores que atuam com alunos surdos (FEITOSA E SILVA, 2017). Nesse contexto, versaremos sobre a importância da formação continuada do professor em Libras e os impactos no desenvolvimento escolar do aluno surdo.

O Artigo 62-A da LDB, em seu parágrafo único, diz que "garantir-se-á formação continuada para os profissionais a que se refere o caput, no local de trabalho ou em instituições de educação básica e superior, incluindo cursos de educação profissional, cursos superiores de graduação plena ou tecnológicos e de pós-graduação". Apesar disso, muitos professores que trabalham na educação de surdos ainda não recebem uma formação de qualidade voltada à perspectiva cultural dos sujeitos surdos, resultando em entraves em seu processo educativo.

Infelizmente, os cursos de licenciatura deixam uma lacuna no tocante à formação de professores aptos para trabalhar com a diversidade, reforçando a necessidade de uma formação consistente e contínua do professor. A formação continuada garante, portanto, um aperfeiçoamento dos saberes dos docentes, uma vez que vivemos em um contexto educacional de constantes mudanças e transformações, possibilitando desta forma, a renovação de suas práticas pedagógicas (FEITOSA E SILVA, 2017).

Além do mais, muitas vezes a carga de trabalho e o curto tempo não favorecem ao interesse para a formação, mas é de suma importância que o professor busque sempre novos conhecimentos na área de educação inclusiva com foco na Libras através da formação continuada, visando a melhoria na qualidade do ensino, uma vez que a própria prática docente se caracteriza como um campo de ação e reflexão (SOUSA, 2017).

No que concerne à metodologia deste trabalho, utilizou-se da pesquisa bibliográfica à artigos e já publicados por autores que abordam o tema apresentado, bem como análise da base legislativa que organiza e regulamenta o sistema educacional no Brasil como a LDB- Lei de Diretrizes e Bases da Educação e a Política Nacional de Educação Especial na Perspectiva da Educação Inclusiva.

\section{FUNDAMENTAÇÃO TEÓRICA}

Apesar dos avanços ocorridos nos últimos anos, é comum encontrar pessoas surdas que ainda sofrem com barreiras linguísticas que atrapalham sua inserção em escolas de ensino regular, dificultando com isso seu desenvolvimento cognitivo. Muitos destes obstáculos estão 
ligados a ausência de estratégias metodológicas adequadas, que em consonância com a falta de profissionais habilitados na Língua Brasileira de Sinais, acarretam um ensino desigual, na qual a singularidade do indivíduo surdo não é respeitada (QUINTELA; GÓES, 2016).

As escolas inclusivas têm como princípio fundamental que a aprendizagem dos alunos, sempre que possível, ocorra de forma igualitária independente das necessidades especiais de cada discente. Deve haver uma boa organização escolar e a devida adequação curricular, em conjunto com a utilização de recursos diversos e estratégias pedagógicas alinhadas visando atender os vários ritmos de aprendizagem dos alunos (Declaração de Salamanca, 1994).

Dentro dessa mesma perspectiva inclusiva, o Decreto $n^{\circ}$ 5626/05 torna obrigatória, no prazo de dez anos da sua publicação, a disciplina de Libras em todos os cursos de Licenciatura e Fonoaudiologia no Brasil:

Art. $3^{\circ}$ A Libras deve ser inserida como disciplina curricular obrigatória nos cursos de formação de professores para o exercício do magistério, em nível médio e superior, e nos cursos de Fonoaudiologia, de instituições de ensino, públicas e privadas, do sistema federal de ensino e dos sistemas de ensino dos Estados, do Distrito Federal e dos Municípios (BRASIL, 2005).

No entanto, é importante frisar que a inserção da disciplina de Libras nos cursos mencionados acima não pode ser a única alternativa para o completo desenvolvimento dos alunos surdos. Em sua pesquisa realizada com alunas do curso de Pedagogia, a pesquisadora Sousa (2017) pôde observar que consideram curta a carga horária da disciplina de Libras no curso de graduação. É importante destacar que o intuito dessa disciplina na grade curricular, não é para que o professor regente que atua em uma sala de aula regular ensine Libras, mas sim que ele consiga se comunicar de forma satisfatória com o aluno surdo e compreenda suas especificidades linguísticas, respeitando sua identidade e cultura enquanto sujeito surdo.

Machado e Lunardi-Lazzarin (2010) afirmam que a formação de professores no campo da inclusão é um dispositivo de governamentalidade dos sujeitos docentes, já que produz efeitos de verdade específicos nos discursos. No atual cenário, a formação docente delineia-se com estratégia precisa na constituição de um corpo de professores interessados e sensibilizados nessa política e vem responder a uma urgência histórica.

Assim, o que se tem percebido é que a formação docente configura-se como o meio que direciona a composição de um grupo de professores que estão intrinsicamente ligados e embrandecidos ao interesse de uma política baseada na constituição do sujeito. Vale a pena destacar, neste momento, a primordialidade da iminência da formação profissional fundada em um conjunto de saberes político-pedagógicos para a estruturação de um corpo docente de 


\title{
A AÇÃO PEDAGÓGICA DO PROFESSOR FRENTE A ABORDAGEM BILINGUE
}

especialistas a fim de que as práticas relacionadas a política instituída sejam garantidas. Conforme ressaltam Machado e Lunardi-Lazzarin (2010, p. 23),

\begin{abstract}
[...] os saberes legitimados pela formação de professores refinam o investimento de poder operado pelas instituições escolares, constituindo-se, nessa engrenagem, como uma estratégia de enquadramento dos sujeitos, especialmente em razão da necessidade de produzir alunos e professores dóceis, maleáveis, administráveis. Nessa paisagem em que se torna indispensável formar um determinado corpo de experts e colocar determinadas práticas em funcionamento, a educação especial constitui -se como uma expertise, um aparato de saber pedagógico emergente no contexto da modernidade para equacionar e continuar produzindo os estranhos - entre eles, os surdos necessários à dinâmica de ordenamento dessa racionalidade.
\end{abstract}

Por esse viés, compreender que a Língua de Sinais é a língua dos surdos e que ela é fundamental para o seu desenvolvimento em todas as esferas como na sociolinguística, na educacional, na cultural e dentre outras, é imprescindível. Conforme, pesquisadores da área da surdez (GÓES, 2002; LACERDA, ALBRES, \& DRAGO, 2013; LODI, 2013; SKLIAR, 1997; SLOMSKI, 2010) conhecedores da essencialidade da Língua de Sinais, os conflitos vivenciados pelos surdos nas situações de inclusão escolar são dadas por razões concernentes à forma peculiar de comunicação e de compreensão do mundo. Eles alertam que a surdez traz implicações referentes à construção identitária, pois os surdos são bilíngues. Nesse sentido, um dos maiores desafios impostos a esse alunado, diante de uma escola pensada e programada para os ouvintes, diz respeito a sua escolaridade (SILVA, 2016).

Há anos vem se discutindo que, perante a lei, os surdos tem direito a Libras como primeira língua (L1) e o português como segunda língua (L2), e isso não é suficiente porque a questão não está somente na efetivação da lei, mas como o professor age frente a essa abordagem bilíngue para que de fato o que é disposto na lei se consolide. Diante dos aspectos abordados sobre a diferença no processo de escrita entre surdos e ouvintes é pertinente ressaltar um relato em que Perlin (2010) retrata de um depoimento de um aluno surdo:

\footnotetext{
É tão difícil escrever. Para fazê-lo, meu esforço tem de ser num clima de despender energias o suficiente demasiado. Escrevo numa língua que não é minha. Na escola fiz todo esforço para entender o significado das palavras usando o dicionário. São palavras soltas elas continuam soltas. Quando se trata de pô-las no papel, de escrever meus pensamentos, elas são marcadas por um silêncio profundo. Eu preciso decodificar o meu pensamento visual com palavras em português que têm signos falados. Muito há que é difícil ser traduzido, pode ser apenas uma síntese aproximada. Tudo parece um silêncio quando se trata da escrita em português, uma tarefa difícil, dificílima (PERLIN, 2010, p.57).
}

Diante do exposto surge o seguinte questionamento: Como ensinar a Língua portuguesa para o aluno surdo? Dentre os métodos adotados na educação dos surdos, o bilinguismo é considerado a proposta mais adequada que consiste em trabalhar as duas línguas no contexto 
escolar, ou seja, Libras e Língua Portuguesa. Para tanto, é necessário que o aluno surdo esteja inserido em um ambiente favorável para a aquisição das duas línguas com um professor formado em um viés bilíngue.

Neste sentido, o bilinguismo define-se como uma condição para inclusão dos estudantes que não ouvem através de processos dialógicos em ambientes nos quais interagem, sejam eles educativos ou não. Ou seja, a partir do seu desenvolvimento inicial por meio da Língua de Sinais é possível acessar e se apropriar dos elementos culturais produzidos pela sociedade, bem como o português, concebido como segunda língua. À luz dessa proposta, as políticas educacionais inclusivas devem assegurar o direito dos surdos de partilharem de sua língua nas escolas públicas de ensino regular (LACERDA, ALBRES, \& DRAGO, 2013; LODI, 2013).

De acordo com Quadros (2011, p. 35) educação de surdos, em uma perspectiva bilíngue, deve ter um currículo organizado em uma perspectiva visualespacial para garantir o acesso a todos os conteúdos escolares na própria língua da criança, a língua de sinais brasileira. Sendo assim, a metodologia bilíngue oferta ao aluno a oportunidade de ter acesso aos conteúdos tanto na sua língua materna Libras, quanto na LP, e assim não se sentindo excluídos do processo de ensino e aprendizagem. De acordo com Quadros (2011, p. 34),

\footnotetext{
A abordagem bilíngue considera a língua de sinais a primeira língua da criança surda, pois, atentando aos resultados das pesquisas em aquisição da linguagem, o acesso a língua de sinais permite o desenvolvimento da linguagem de forma natural e espontânea, podendo ocorrer de forma análoga ao processo de crianças adquirindo quaisquer outras línguas.
}

Considera-se, entretanto, que o desenvolvimento de propostas no viés bilíngue dentro do âmbito escolar tem sido um desafio constante para profissionais da educação, intérpretes e gestores escolares (SILVA, 2016). Embora, a escola assegure o intérprete que, de certa maneira, permite ao surdo uma comunicação através da Língua de Sinais, ela pode esta limitando à uma "inclusão como território, como espaço, como concepção de uma escola em que a Língua de Sinais passe apenas pela tradução da língua oral” (GIORDANI, 2004, p. 97 98). Isto é, o trabalho escolar em que essa língua representa apenas um instrumento pedagógico, descaracterizando-a como linguagem genuína em sua plenitude (SOUZA \& LIPPE, 2012; WITKOSKI \& BAIBICH-FARIA, 2010).

Por conseguinte, os paradigmas pedagógicos que norteiam o modelo bilíngue se consolidaram na última década no Brasil, sendo os responsáveis pelas transformações na concepção ideológica sobre o que é ser surdo e possibilitando as formas organizativas de ensino mais significativos a esse público (FERNANDES \& MOREIRA, 2009; SKLIAR, 1997/2006). Mediante as diferentes modalidades de ensino e variadas interpretações sobre o 


\section{A AÇÃO PEDAGÓGICA DO PROFESSOR FRENTE A ABORDAGEM BILINGUE}

que vem a ser bilinguismo, essa abordagem educacional aponta para composição de práticas educacionais que consideram a centralidade dos aspectos linguísticos e sociais para a cultura surda (SILVA, 2016).

Com isso, é imprescindível que o professor tenha uma experiência formativa na Libras e o aluno surdo no âmbito da inclusão seja atendido por meio de propostas educacionais conforme às suas necessidades. Nesse sentido, o uso do visual no processo de ensino e aprendizagem possibilita sanar as barreiras da aprendizagem e, sobretudo da comunicação.

Portanto, é necessário que para o aprendizado da leitura e escrita as atividades sejam antecedidas pela leitura em Libras de forma contextualizada e partindo desse método eles sintam interesse em participar desse processo Quadros (2011, p. 41), deixa claro ao dizer que

O professor vai precisar dar instrumentos para o seu aluno chegar à compreensão. Provocar nos alunos o interesse pelo tema da leitura por meio de uma discussão prévia do assunto, ou de um estímulo visual sobre o mesmo, ou por meio de uma brincadeira ou atividade que os conduza ao tema pode facilitar a compreensão do texto.

Isso significa, que ninguém aprende sem estar estimulado, o fato do aluno surdo não gostar ou não adquirir habilidades na leitura e escrita esta geralmente ligada a falta de estímulos no ambiente escolar, sob ótica de muitos autores como Gesser (2012) muitos surdos relatam não sentir interesse pela LP, pelo fato de algumas memórias negativas como a imposição do português a todo custo na escolarização e tendo a negação da língua de sinais na alfabetização.

Essa afirmativa está atrelada a experiência formativa do professor, embora o artigo 10 do Decreto 5.626 atesta que "As instituições de educação superior devem incluir a Libras como objeto de ensino, pesquisa e extensão nos cursos de formação de professores para a educação básica, nos cursos de Fonoaudiologia e nos cursos de Tradução e Interpretação de Libras Língua Portuguesa" (BRASIL, 2005). Percebe-se, que ainda não há uma diretriz ou um modelo já consolidado sobre como deve ser a educação de surdos; a sensação dos professores, de acordo com Santos (2011), é de limitações na formação para o atendimento desse alunado frente à sua peculiaridade linguística.

Assim sendo, é baseado nesse contexto educacional que a formação continuada do professor em Libras integra esse novo processo inclusivo do sistema escolar, assumindo um papel muito importante, uma vez que se torna essencial essa especialização para atender as necessidades dos alunos surdos (PIASSON et al., 2018), levando em consideração as suas particularidades e necessidades educacionais especiais (FERNANDES e REIS, 2019). Silva (2016), reitera que esses aspectos merecem ser considerados para efetivar um ensino bilíngue de qualidade para os surdos colocando em destaque todos os profissionais que atuam com esses alunos nas escolas. 


\section{METODOLOGIA}

A pesquisa bibliográfica, de acordo com Gil "é desenvolvida a partir de material já elaborado, constituído principalmente de livros e artigos científicos" (2008, p. 50) e tem como principal benefício expandir o campo de pesquisa do investigador, o que não seria possível em uma pesquisa direta. De caráter bibliográfico, com intuito de aprofundar as nossas discussões e elencarmos o que encontramos no campo teórico, esse tipo de metodologia torna-se indispensável para elaboração do presente trabalho.

Dentro dessa proposta, recorremos a pesquisas em revistas científicas e em materiais já desenvolvidos por autores que dissertam sobre o objeto de estudo, uma vez que "as pesquisas que se valem de dados existentes permitem resultados mais acurados nas pesquisas referentes" (GIL, 2008, p. 154) enriquecendo assim, os dados para análise da situação problema, utilizando como base estudos publicados por (CRUZ E COSTA, FEITOSA E SILVA, SILVA E ARAÚJO, PIASSON et. al., 2018).

Com base no que foi exposto nas sessões anteriores, na ênfase à valorização do caminho do meio, ou seja, o da interação da ação do professor frente a abordagem bilíngue em Libras. O desenvolvimento dessa pesquisa surge a partir da necessidade de promover vivências e práticas em Libras, de modo a favorecer o conhecimento da cultura, língua e identidade surda pelos estudantes e docentes ouvintes.

\section{RESULTADOS E DISCUSSÃO}

Com base dos trabalhos pesquisados, foi possível observar que ocorreu um grande avanço na Educação Inclusiva com a oferta da disciplina de Libras nos cursos de Licenciatura e Pedagogia, porém esse é apenas o primeiro passo para que os alunos surdos incluídos nas escolas de ensino regular tenham o apoio necessário. Visto que, a realidade exige esforços além dos conhecimentos adquiridos pelos professores na graduação.

Pudemos observar como é importante que o professor busque por formação continuada na área de Libras, uma vez que a presença de um intérprete de Libras em sala não supre em sua totalidade as necessidades do discente com surdez. Uma vez que o professor se qualifica, ele consegue compreender quais são as reais dificuldades do seu aluno, levando em consideração todas as particularidades do discente surdo enquanto sujeito que se comunica através de outra língua e tem uma cultura diferente dos demais alunos ouvintes.

Por intermédio dos estudos de Cordeiro (2018), ressaltamos que embora o conhecimento da Língua Brasileira de Sinais pelo professores tem avançado significativamente e ainda que o 


\section{A AÇÃO PEDAGÓGICA DO PROFESSOR FRENTE A ABORDAGEM BILINGUE}

docente esteja disposto a conhecer e interagir com o aluno de forma igualitária promovendo à uma proposta inclusiva na qual as escolas estão inseridas, isso não quer dizer que terá os subsídios suficientes para que todas as necessidades educacionais do aluno surdo sejam atendidas. Consolidar o cenário da educação bilíngue para os surdos constituir-se um fator ideal para o seu desenvolvimento, pois considera seu sistema linguístico bem como os seus aspectos culturais.

Figura 01: Tipo de linguagem utilizada pelos professores para se expressar com os alunos surdos.

Tipo de linguagem utilizada pelos professores para se expressar com os alunos surdos

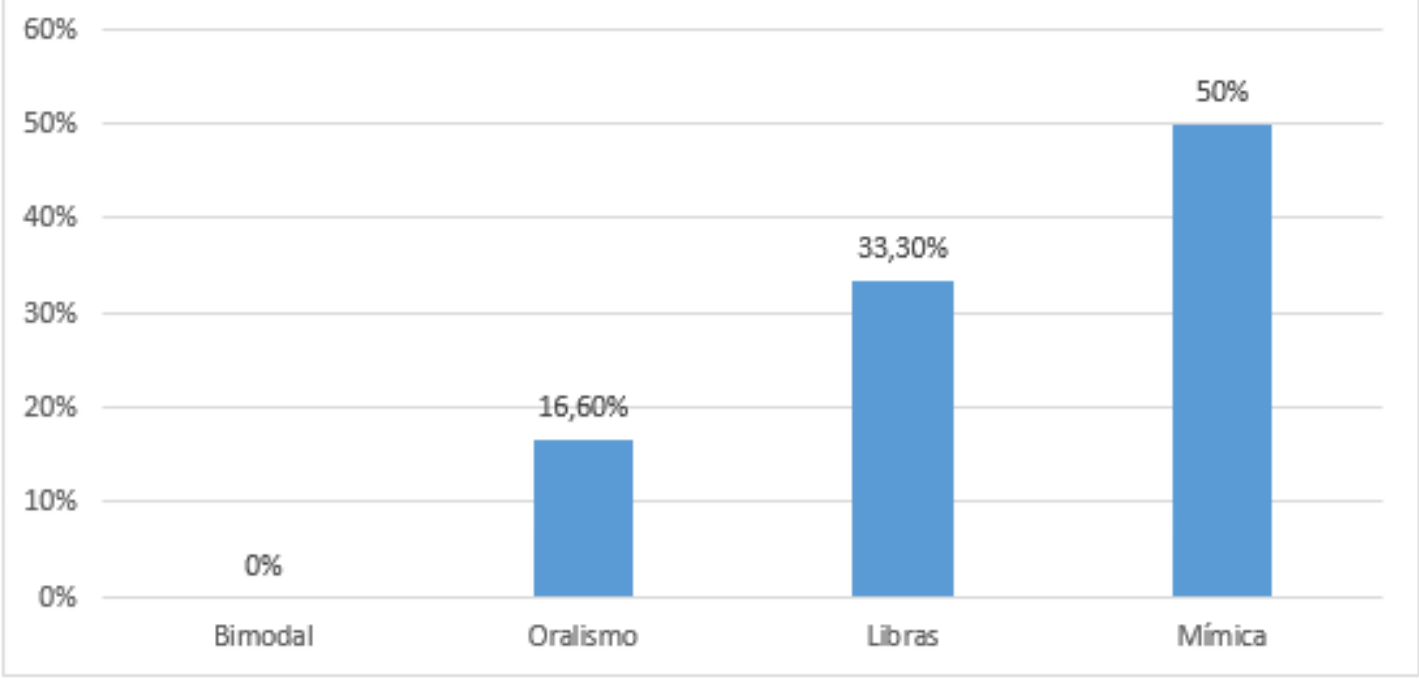

Fonte: Cordeiro (2018).

Destaca-se ainda, que o saber da Língua Brasileira de Sinais é um saber especializado que vai tomando espaço e forma que legitimam linguisticamente a comunidade surda, abrindo caminhos e possibilidades para a efetivação da educação bilíngue para os surdos na atualidade. O que temos visto, segundo os estudos de Cordeiro (2018) é possível encontrar cotidianamente professores utilizam-se de outras formas comunicativas para se expressar com os alunos surdos e em sua maioria por gestos.

Apesar disso, é perceptível que com a visualidade da Libras no contexto social e o quanto a comunicação tem ocorrido por intermédio da Libras com o apoio dos intérpretes de Libras e aumento significativo dos cursos de Libras. Isto, vem demostrando cada vez mais a aproximação e efetivação de uma educação pautada no bilinguismo. Assim, aponta também o estudo realizado por Cordeiro (2018), que 50\% dos professores que buscam conhecimento conseguem se comunicar por meio de sinais básicos da Libras com seus alunos surdos. 
Figura 02: Demonstrativo do nível de conhecimento dos professores que conseguem se comunicar em Libras.

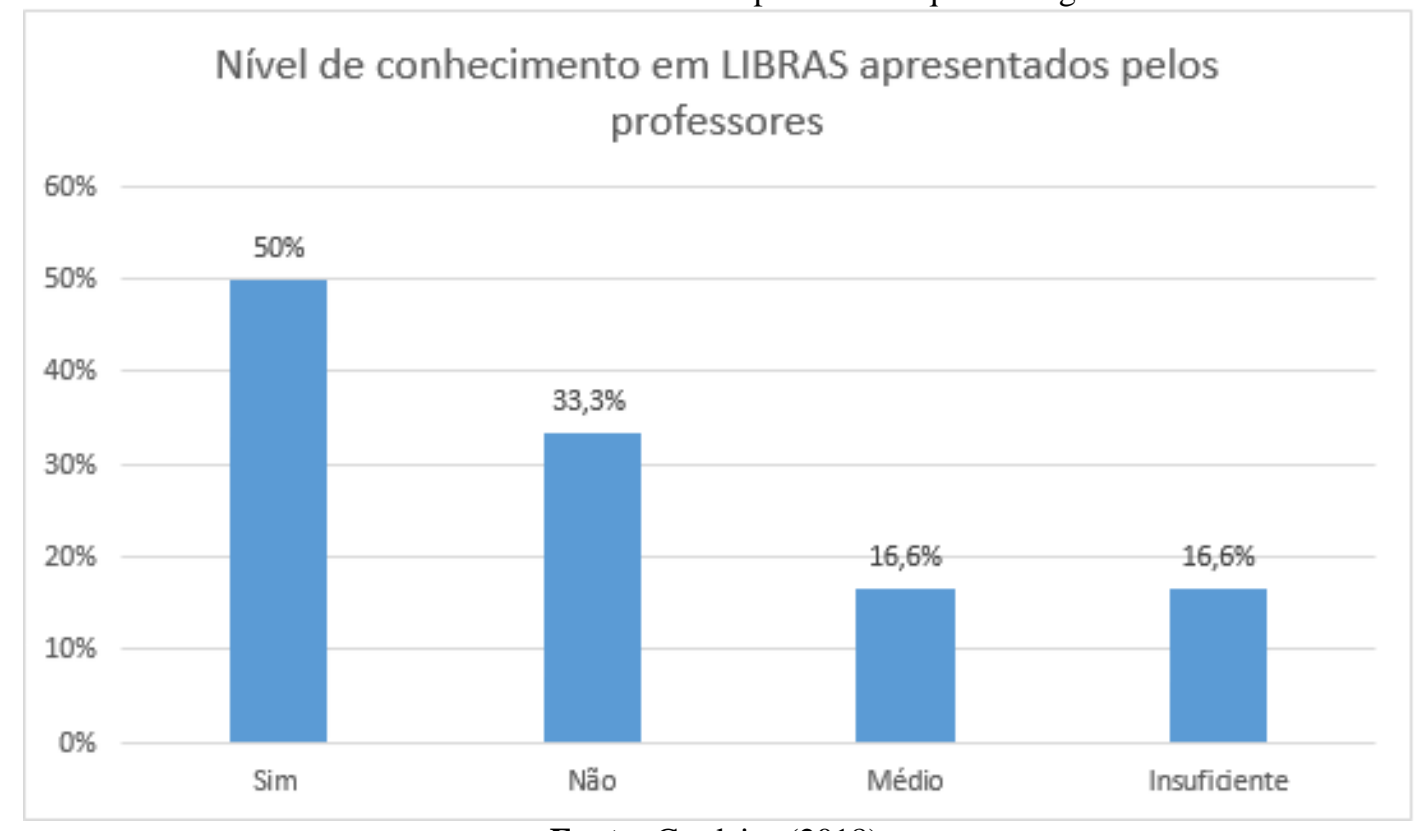

Fonte: Cordeiro (2018).

Em suma, é possível compreender que a educação de surdos consolidada numa perspectiva de legitimidade nos aspectos linguísticos é fundamental para o pleno desenvolvimento do educando surdo tornando-se assim, um desafio inerente à educação brasileira. E no que diz respeito ao bilinguismo, será um processo que acontecerá em longo prazo até que se consolide. Visto que, para que isso aconteça é necessária toda uma mudança no cenário educacional e não somente no que competem as políticas públicas, mas em toda formação e na conscientização dos profissionais que atuam na área.

À vista disto, estes profissionais precisam excluir do vocabulário frases como: "Como vou ensinar ao surdo se não sei Libras", "O aluno surdo é responsabilidade do intérprete", "Não fui capacitado para ensinar em Libras", dentre outras que são comuns serem ouvidas por professores que têm alunos surdos. Mas sim, adentrar nessa comunidade singular, aprender a língua de uso, compreender sua cultura. E dessa forma, terão subsídios necessários para proporcionar uma aprendizagem significativa e de sucesso a todos seus alunos, inclusive, os surdos.

\section{CONCLUSÕES}

Com o estudo sobre a ação do professor frente a abordagem bilíngue em Libras, inferimos que a formação continuada em Libras para os docentes é considerada uma prática de extrema importância, visto que cada vez mais alunos surdos estão ingressando em escolas de ensino regular. O conhecimento da língua do aluno é o primeiro passo para que o professor 


\section{A AÇÃO PEDAGÓGICA DO PROFESSOR FRENTE A ABORDAGEM BILINGUE}

consiga se comunicar efetivamente com o discente sem a dependência do intérprete de Libras, possibilitando a ressignificação de sua prática docente e bem como vislumbrar novos meios de incluir de fato o aluno surdo em suas práticas educacionais.

No decurso deste texto, foi possível constatar que a formação dos professores de surdos está intrinsecamente relacionada à constituição do conceito de educação bilíngue e que tanto a formação como a educação bilíngue têm seus conceitos interligados. Também no decorrer do texto, pôde-se notar que a compreensão a respeito da surdez e como ela está correlacionada as práticas dos professores, e dessa forma pode contribuir para constituição desses profissionais a partir de diferentes direções que esse forma educacional singular propõe.

Para tanto, é de suma importância que as instituições educacionais promovam formações para os seus docentes, aprimoramento cada vez mais suas competências e consequentemente elevando a qualidade do ensino e da aprendizagem. É importante frisar que o conhecimento da Libras pelo docente é apenas uma atitude inicial para que o desenvolvimento do aluno surdo ocorra de forma satisfatória, uma vez que é necessário também que o professor tenha conhecimento acerca das metodologias de ensino alinhadas com a cultura surda, visto que sua percepção é espaço-visual, diferentemente dos alunos ouvintes que são a grande maioria das escolas de ensino regular.

Levando-se em conta o que foi observado, a aquisição de novos conhecimentos sobre a Língua Brasileira de Sinais e até mesmo acerca da cultura surda, tornará o professor um agente de transformação no ambiente educacional, difundindo práticas inclusivas e proporcionando uma educação igualitária entre todos os alunos.

A partir dessas observações o que nos inquieta é como está o desenvolvimento do aluno surdo na sala regular de ensino em relação a não utilização de recursos visuais que são de suma importância para o desenvolvimento da aprendizagem do estudante surdo, visto que sua língua natural possui uma estrutura visual espacial e a não utilização desses recursos, evidenciou uma barreira educacional durante todo o seu processo de aprendizagem.

Em virtude do que foi mencionado, podemos auferir que o desenvolvimento do aluno surdo a partir das práticas pedagógicas propostas no ambiente escolar necessita ser repensadas. Por esse víeis, o professor da sala regular de ensino deve agir considerando as particularidades dos estudantes surdos, como afirmam as autoras Ana Lodi e Cristina Lacerda (2014, p. 116) "os professores assumem a difícil tarefa de ensinar a todos os alunos conforme as suas necessidades e peculiaridades de aprendizado e de desenvolvimento". Sendo assim, a sua formação torna-se desafiadora no que diz respeito a Educação Inclusiva com foco na Libras.

Contudo, reconhecer o uso da Libras na educação dos surdos é um passo de grande 
importância, já que é por meio desta que esses alunos irão desenvolver suas habilidades de leitura e de escrita. Desse modo, buscar metodologias adequadas para esse processo aconteça com excelência é primordial, mas para isso é necessário que o professor tenha uma postura didática pautada sob uma abordagem bilíngue. No qual, sejam ofertadas propostas metodológicas voltadas as experiências que envolvem a língua natural (L1) e é isto, que de fato essa pesquisa evidencia, que o aluno só avança a partir do seu respeito linguístico.

Espera-se que esse trabalho sirva de fonte para outras discussões relacionadas a formação pedagógica do professor frente a uma abordagem bilíngue para alunos surdos, bem como o levantamento de novos estudos que contribuam significativamente para o processo de ensino e aprendizagem desse estudante.

\section{REFERÊNCIAS}

BRASIL. Congresso Nacional. Lei n 10.436, de 24 de abril de 2002. Dispõe sobre a Língua Brasileira de Sinais - Libras e dá outras providencias. Brasília, 2002.

Declaração de Salamanca e Linha de Ação sobre Necessidades Educativas Especiais. Brasília: Coordenadoria Nacional para Integração da Pessoa Portadora de Deficiência, 1994. Disponível em $<\quad$ http://www.dbd.pucrio.br/pergamum/tesesabertas/0621147_10_postextual.pdf> Acesso em 26 de set. 2020.

. Lei Federal no 9394 de 20 de dezembro de 1996. Diretrizes e Bases da Educação Nacional. Diário Oficial da República Federativa do Brasil. Brasília, 1996. Disponível em <http://www.planalto.gov.br/ccivil_03/leis/19394.htm> Acesso em 26 de set. 2020.

Ministério da Educação. Marcos político-legais da educação especial na perspectiva da educação inclusiva. Brasília: Secretaria de Educação Especial, 2010.

Ministério da Educação. Política Nacional de Educação Especial na Perspectiva da Educação Inclusiva. Brasília: Secretaria de Educação. Especial - MEC; SEESP, 2008.

Decreto no 5.626, de 22 de dezembro de 2005. Regulamenta a Lei n 10.436, de 24 de abril de 2002, que dispõe sobre Língua Brasileira de Sinais - Libras, e o artigo. 18 da Lei n 10.098, de 19 de dezembro de 2000. Brasília 2005.

CORDEIRO, Jéssica Lima, SILVA, Maysa Sousa. O ensino de ciências e biologia na educação dos surdos: desafios e perspectivas para uma melhor educação inclusiva. Revista Científica Multidisciplinar Núcleo do Conhecimento. Ano 03, Ed. 08, Vol. 14, pp. 86-100, Agosto de 2018. Disponível em < https://www.nucleodoconhecimento.com.br/educacao/ciencias-ebiologia> Acesso em 10 out. 2020

CRUZ, Evandro Costa; COSTA, Deuzeli Brandão da. A Importância da Formação Continuada e sua Relação com a Prática Docente. Revista Científica Multidisciplinar Núcleo do Conhecimento. Edição 08. Ano 02, Vol. 03. Pág. 42-58, Novembro de 2017. Disponível em 
$<$ https://www.nucleodoconhecimento.com.br/educacao/formacao-continuada> Acesso em 26 set. 2020.

FERNANDES, Jomara Mendes; REIS, Ivoni de Freitas. O papel da formação continuada no trabalho dos professores de Química com alunos Surdos. Revista Educação Especial | v. 32 | 2019 - Santa Maria. <https://periodicos.ufsm.br/educacaoespecial/article/view/27300/pdf_1 > Acesso em 28 set. 2020.

FERNANDES, S. \& MOREIRA, L.C. Desdobramentos político-pedagógicos do bilinguismo para surdos: reflexões e encaminhamentos. Revista de Educação Especial, 22 (34), 2009.

FEITOSA, Claudinéia; SILVA, Kelly Suemia Dutra. A Formação Continuada em Libras para Professores da Educação Básica: A Experiência da Secretaria Municipal de Educação de JataíGo. Anais da Semana de Licenciatura, Jataí, GO, p. 82-87, out. 2017. ISSN 2179-6076. Disponível em: < http://revistas.ifg.edu.br/semlic/article/view/578 >. Acesso em 28 set. 2020.

FREIRE, Paulo. Política e Educação. 5a ed. São Paulo: Cortez, 2001.

GESSER, Audrei. Libras? Que língua é essa? Crenças e preconceitos em torno da Língua de sinais e da realidade surda. 1 Ed. São Paulo: editora Parábola, 2009.

O Ouvinte e a Surdez. Sobre ensinar e aprender a libras. 1 Ed. São Paulo:

Editora Parábola, 2012.

GIL, Antônio Carlos. Métodos e Técnicas de Pesquisa Social. $6^{a}$ edição - São Paulo: Atlas S.A, 2008.

GIORDANI, L. F. Representações culturais da escrita: letramentos e educação de jovens e adultos surdos. Anais do Seminário de Pesquisa em Educação da Região Sul. Curitiba: Seminário de Pesquisa em Educação da Região Sul, 2004.

GÓES, M. C. R. Linguagem, surdez e educação ( $3^{\text {a }}$ ed.). Campinas, SP: Autores Associados, 2002.

LACERDA, C.B. F., ALBRES, N. A., DRAGO, S.L.S. Política para uma educação bilíngue e inclusiva a alunos surdos no município de São Paulo. Educação e Pesquisa, 2013.

LODI, Ana Claudia Balieiro. Educação bilíngue para surdos e inclusão segundo a Política Nacional de Educação Especial e o Decreto no 5.626/05. Educ. Pesqui., São Paulo, mar. 2013. Disponível em <http://www.scielo.br/scielo.php?script=sci_arttext\&pid=S151797022013000100004\&lng=pt\&nrm=iso>. Acesso em 14 out. 2020.

MACHADO, Fernanda; LUNARDI-LAZZARIN, Márcia Lise. Formar, tolerar, incluir: tríade de governamento dos professores de surdos. Cadernos de Educação, Pelotas, Faculdade de Educação - UFPel, ano 19, n. 36, p. 19-44, maio/ago. 2010

PERLIN, G.T.T. Identidades Surdas. In: SKLIAR, C. (Org.). A surdez: um olhar sobre as diferenças. 4.ed. Porto Alegre: Mediação, 2010. 
PIASSON, Valdineia Ferreira dos Santos; SOUZA, Renata Aparecida de; NEGREIROS, Cláudia Landin; KOCHHANN, Maria Elizabete Rambo. Libras e Formação Docente: Desafios para o ensino de matemática. COINSPIRAÇÃO - Revista de Professores que ensinam Matemática. v. 1, n. 1 Janeiro a Junho 2018. Disponível em: <http://sbemmatogrosso.com.br/publicacoes/index.php/coinspiracao/article/view/17/11 > Acesso em 28 set. 2020.

QUADROS, Ronice Muller de. SCHMIEDT, Magali L.P. Ideias para ensinar português para alunos surdos. Brasília: MEC SE ESPERO 2006.

Ronice Muller de. KARNOPP, Lodenir Becker. Língua de sinais brasileira: Estudos linguísticos. Editora: Artmed, Porto Alegre, 2004.

Ronice Muller de. KARNOPP, CRUZ, Carina Rebello. Língua de sinais Instrumentos de Avaliação. Editora: Artmed, Porto Alegre, 2011.

Ronice Muller de. KARNOPP, LEITE, Tarcísio de Arantes. STUMPF, Marianne. Estudos da Língua Brasileira de Sinais. Editora: Insular, Florianópolis, 2014.

QUINTELA, R. M; GÓES, E. P. Atendimento Educacional Especializado de surdos na Educação de Jovens e Adultos (EJA): Jogos de Geometria. Cadernos PDE - Governo do Paraná. Vol. 2016.20 Disponível em: <http://www.diaadiaeducacao.pr.gov.br/portals/cadernospde/pdebusca/producoes_pde/2016/2 016_artigo_edespecial_unioeste_rozislandamoreiraquintela.pdf>. Acesso em: 23 set. 2020.

SANTOS, K.R.O.R.P. Formação continuada e necessidades formativas de professores na educação de surdos da rede pública da cidade do Rio de Janeiro. Tese de Doutorado, Universidade Metodista de Piracicaba, Programa de Pós Graduação em Educação, São Paulo, 2011.

SILVA, Everson Melquiades Araújo; ARAÚJO, Clarissa Martins de Araújo. Reflexão em Paulo Freire: uma contribuição para a formação continuada de professores. V Colóquio Internacional Paulo Freire - Recife, 19 a 22 setembro 2005. Disponível em <http://189.28.128.100/nutricao/docs/Enpacs/pesquisaArtigos/reflexao_em_paulo_freire_200 5.pdf $>$ Acesso em 26 set. 2020.

SILVA, Carine Mendes da; SILVA, Daniele Nunes Henrique. Libras na educação de surdos: o que dizem os profissionais da escola? Psicol. Esc. Educ., Maringá, v. 20, n. 1, p. 33- 44, Abr. 2016. Disponível em: <http://www.scielo.br/scielo.php?script=sci_arttext\&pid=S141385572016000100033\&lng=en\&nrm=iso>. Acessado em: 12 Out. 2020.

SOUZA, R. M. \& Lippe, E. M.O. Decreto 6.949/2009: avanço ou retorno em relação à Educação dos Surdos? Caleidoscópio, 10(1), 12-23, 2012.

SOUSA, Júlia Leyne Andrade de. A percepção de discentes do curso de pedagogia da UEPB sobre a disciplina LIBRAS: a formação inicial em foco. 2017. 38f. Trabalho de Conclusão de Curso (Graduação em Pedagogia) - Universidade Estadual da Paraíba, Campina Grande, 2017. Disponível em: <http://dspace.bc.uepb.edu.br/jspui/bitstream/123456789/15233/1/PDF\%20$\% 20 \mathrm{~J} \%$ c3\%balia\%20Leyne\%20Andrade\%20de\%20Sousa.pdf> Acesso em 28 set. 2020. 
SLOMSKI, V. G. Educação Bilíngue para surdos: concepções e implicações práticas (1a. ed.) Curitiba: Editora Juruá, 2010.

SKLIAR, C. (Org.). Educação \& exclusão: abordagens sócioantropológicas em educação especial ( $5^{\text {a }}$ ed.). Porto Alegre: Mediação. (Trabalho original publicado em 1997), 2006.

VIEIRA-MACHADO, Lucyenne Matos da Costa; LOPES, Maura Corcini. A Constituição de uma Educação Bilíngue e a Formação dos Professores de Surdos. Educ. Real., Porto Alegre, Set. 2016. Disponível em: <http://www.scielo.br/scielo.php?script=sci_arttext\&pid=S217562362016000300639\&lng=en\&nrm=iso >. Acessado em: 12 Out. 2020.

WITKOSKI, S. A. BAIBICH-FARIA, T. M. A importância da Língua de Sinais para as pessoas surdas na construção de uma linguagem plena e genuína. Revista Contrapontos, 10(3), 338$344,2010$. 